\title{
Corrigendum
}

\section{Utility of small biopsies for diagnosis of lung nodules: doing more with less}

Sanjay Mukhopadhyay

Modern Pathology (2012) 25, 1054; doi:10.1038/modpathol.2012.42

Correction to: Modem Pathology (2012) 25, S43-S57; doi:10.1038/modpathol.2011.153
In this article, there is an error on page S45, right column, fourth line from the bottom of the column: the reference citation should be '12,' not 11. 